\title{
Household Social Environmental Influences on African-American Adolescents' Smoking Habits
}

\author{
Larry J. Bell ${ }^{1}$, William H. Zimmerli ${ }^{2}$, David F. Duncan ${ }^{3}$ \\ ${ }^{1}$ Fulton County Department of Health and Wellness \\ ${ }^{2}$ Fort Valley State University \\ ${ }^{3}$ Duncan \& Associates
}

\begin{abstract}
Because most smokers begin smoking during adolescence and because there are few studies that focus on African-American adolescent's smoking behavior, the purpose of this study was to determine if a significant difference exists in the prevalence of smoking between African-American adolescent teens living with household members who smoke and those living with household members who do not smoke. The subjects in this study were 585 adolescents (342 females and 243 males) who received services at the Center Hill Health Center from 2001 to 2004. The data was collected from the medical records of the clients selected for this study. The data in this study was analyzed using chi square tests of independence. The first analysis revealed that a significant difference existed between the smoking status of the household members of adolescents who were smokers compared to those who where non- smokers $\left(\chi^{2}=\right.$ $14.58, \mathrm{df}=1, \mathrm{p}<.05$.$) .$
\end{abstract}

(C) 2007 Californian Journal of Health Promotion. All rights reserved.

Keywords: tobacco, smoking, African-American, adolescents.

Tobacco use is one of the most important causes of preventable death in the United States. Approximately 435,000 people die each year because of smoking, and it is responsible for nearly one in five deaths in the United States (Mokdad, Marks, Stroup, \& Gerberding, 2004). Further, it is estimated that 80 percent of those who use tobacco begin before the age of 18 (U.S. Department of Health and Human Services, 1994). In 2002, the prevalence of tobacco use was 28.4 percent among high school students (Centers for Disease Control and Prevention, 2003). During 2005, a total of 23.0\% of high school students had smoked cigarettes during the 30 days preceding the Youth Risk Behavior Surveillance System survey (Eaton et al., 2006). As a significant modifiable risk factor, tobacco use prevention has become a key public health initiative. Concern over tobacco use among adolescents has prompted the creation of several Healthy People 2010 objectives, especially among ethnic and racial groups.
African-American adolescents are less likely to be smokers than are White adolescents. In 1999, current smoking was reported by $19.7 \%$ of African-American high school students (17.7\% of females and $21.8 \%$ of males) compared to $38.6 \%$ of White students $(39.1 \%$ of females and $38.2 \%$ of males) (Centers for Disease Control and Prevention, 2000). In recent years, smoking has started to increase among African American male teens, but African American female teens continue to have lower smoking rates (Centers for Disease Control and Prevention, 1998). In 1997, 40 percent of white high school females were smokers, compared to 17 percent of African American high school females.

Numerous studies (e.g., Kandel and $\mathrm{Wu}, 1995$; Males, 1995; Palmer, 1970; Patton et al., 1998; Salber and MacMahon, 1961; Simons-Morton et al., 2001) have shown an association between parental smoking and smoking by teen students. This has even been found in one study of parents and teen students in Zhejiang Province, China (Hesketh, Ding \& Tomkins, 2001). Several 
studies have identified maternal smoking as being particularly influential on adolescent smoking (Brook et al., 1981; Brook et al., 1997; Lieb, Schreier, Pfister, \& Wittchen, 2003).

Burchfield, Higgins, Keller, Butler, and Donahue (1989) broadened the issue by examining the risk for smoking initiation in adolescents who were raised in homes with any household members who were smokers. Their survey of 3,482 adolescents found that those who lived with household members who smoked were at greater risk of becoming smokers themselves. Johnson et al. (2002) similarly found in their cohort study of 3,654 students that tobacco use by parents, siblings, and friends, and easy accessibility in the home in fifth grade, were significant predictors for smoking in eighth grade.

Boomsma et al. (1994), on the other hand, reached a contrary conclusion in their twin study of parental smoking's impact on teen smoking behavior. Based on their survey of 1,582 adolescent twin pairs and their parents they drew two conclusions: First, that adolescent smoking behavior is not directly influenced by the smoking behavior of their parents. Second, that the environmental factors that influence smoking in boys differ from the environmental factors that influence smoking in girls.

None of the preceding studies, however, examined this subject among African-American adolescent. This may be an important gap in our knowledge of the problem. Gritz et al. (1995), for example, found that the factors associated with ever smoking and susceptibility to smoking differed among White, African-American, and Hispanic adolescents. Other researchers, such as Johnson et al. (2002), have found no racial differences in the predictors of teen smoking. Johnson et al. also found no difference between males and females in the influence of parental smoking or other influences on smoking.

In one of the six published studies to examine this specific issue in African-American adolescents, Botvin, Baker, Goldberg, Dusenbury, and Botvin (1992) examined the correlates and predictors of cigarette smoking among 687 African-Americans attending nine junior high schools. Their findings indicated that smoking initiation among black adolescents may be largely attributed to peer influences. Furthermore, knowledge of the adverse health effects of smoking had little effect and parental factors played a negligible role in cigarette smoking in this population.

Kurtz, Kurtz, Johnson, and Beverly (1996) also collected data on this subject from AfricanAmerican youth in the context of their study of environmental tobacco smoke exposure. They surveyed 675 students enrolled in grades five through twelve in an urban public school district located in the greater metropolitan area of Detroit, Michigan. Smoking rates among students were higher if someone else in the home was a smoker and lower if there were no other smokers in the home. Forty-eight percent of the students reported that their fathers smoked, while $46 \%$ reported mothers who smoked. Anti-smoking attitude scores were higher if the mother or father was a nonsmoker. Students' tobacco-related knowledge was significantly predicted by their gender and school level and by the proportion of their siblings who were smokers.

Griesler and Kandel (1998) examined influences on adolescent smoking in 1,795 mother-child dyads from the 1992 National Longitudinal Survey of Youth. Maternal smoking was an important factor for White adolescents only. The lack of effects of maternal smoking and perceived peer pressure to smoke on AfricanAmerican adolescents compared with whites suggested to the researchers that role modeling and interpersonal influence may be more important determinants of smoking for White than for African-American adolescents.

Alexander, Allen, Crawford, and McCormick (1999) conducted focus groups with African American, Whites, Hispanic American, and Native American adolescents in which they examined influences on initiation of smoking. They found that parental influence played an important role for White and Hispanic American adolescents but was not a common factor for 
African American or Native American adolescents.

Dornelas et al. (2005) surveyed 181 adolescent subjects from three focal ethnic groups (White $=$ 138; African American = 24; Hispanic $=19$ ) who had smoked at least 100 cigarettes in their lifetime and were current smokers. These subjects were a subset of a larger sample of 1,305 adolescents from four ethnically and geographically diverse sites in the United States who were surveyed in a 1999 needs assessment. Almost all (96\%) of the African American adolescents lived with another smoker compared to $68 \%$ of Hispanic and $60 \%$ of Whites ( $p=$ $.004)$. African-American teens were more likely to smoke with family members $(50 \%)$ than Hispanics $(5 \%)$ or whites $(25 \%)$. In addition, African-American teens in this study emphasized the familial and social pressures of smoking. Higher rates of acceptance of smoking by family members, role modeling by household members, more prevalent beliefs that smoking is a way to achieve belonging, and lack of perceived support for quitting by friends appear to influence cigarette smoking more for AfricanAmerican than for White or Hispanic youth.

Brook, Pahl, and Ning (2006) identified trajectories of smoking behavior during a period extending from adolescence to young adulthood among urban African Americans and Puerto Ricans. For both ethnic/racial groups, the same four distinct trajectories were identified: nonsmokers, maturing-out smokers, late-starting smokers, and early-starting continuous smokers. African Americans were over-represented in the nonsmoking group, whereas Puerto Ricans were over-represented in the early-starting continuous group. Females were more likely than males to be early-starting continuous smokers and less likely to be late starters.

\section{Methods}

The hypothesis of this study was that a significant difference exists in the prevalence of Those who were exposed to peer and parental smoking in early adolescence were more likely to belong to trajectory groups characterized by higher levels of smoking.

The subjects for this study were all AfricanAmerican adolescents between the ages of 10 and 19 years who received health services for the first time at the Center Hill Health Center Adolescent Clinic between 2001 and 2004. The Center Hill Health Center of the Fulton County Department of Health and Wellness is located in an inner city area of northwest Atlanta. Over 90 percent of the patients who receive services at the center are African American.

Data was collected from the health history and the smoking cessation questionnaire contained in the medical records of the patients. The health history contained all the demographic information on the patient, including family members who smoke. The smoking cessation questionnaire is a tool used by the adolescent clinic to assess tobacco use by its clients. Any client who reports tobacco use is provided with access to smoking cessation counseling.

\section{Results}

The medical records of 619 patients were reviewed for this study. Of that number, 585 records were included in the study. Data required for the study was missing from 24 records that were excluded. A further ten were excluded because the patient was outside the age parameters of 10 to 19 years. Only 30 (5.1\%) of the patients were smokers. This included 9 males and 21 females. The 555 (94.9\%) smokers included 321 females and 234 males. Table 1 summarizes the smoking status of the adolescent patients categorized by age and gender.

The adolescent' medical records provided information on the smoking status of 1,950 household members. Three-hundred-nine $(15.7 \%)$ household members were reported to be smokers and 1,641 were non-smokers. Table 2 details the smoking status and relationship to the adolescents of the household members. 
Table 1

Smoking Status of Subjects by Age and Gender

\begin{tabular}{|l|c|c|c|c|c|}
\hline & \multicolumn{2}{|c|}{ Smokers } & \multicolumn{2}{c|}{ Non-smokers } & Total \\
\hline Age Range & Male & Female & Male & Female & \\
\hline $\mathbf{1 0 - 1 4}$ & 1 & 0 & 137 & 123 & 261 \\
\hline $\mathbf{1 5 - 1 7}$ & 5 & 11 & 80 & 147 & 243 \\
\hline $\mathbf{1 8 - 1 9}$ & 3 & 10 & 17 & 51 & 81 \\
\hline All ages & 9 & 21 & 234 & 321 & \\
\hline Total & \multicolumn{3}{|c|}{30} & \multicolumn{3}{|c|}{555} & 585 \\
\hline
\end{tabular}

Categorizing the adolescents' households as those including smokers and those with no smokers, a chi square analysis was conducted of the numbers of smoking and non-smoking adolescents in each (see Table 3). Of the 350 adolescents living in households with no smokers, 8 were themselves smokers. Of the 235 who lived with at least one smoker, 22 were smokers. The prevalence of smoking among these African-American adolescents was, thus, found to be significantly related to smoking by other household members $\left(\chi^{2}=14.58\right.$, d.f. $=1, p$ $<.05)$.

Table 2

Household Members' Smoking Status and Their Relationship to the Adolescents

\begin{tabular}{|l|c|c|c|}
\hline Household members & Smokers & Non-smokers & Total \\
\hline Mother & 191 & 360 & 551 \\
\hline Father & 90 & 220 & 310 \\
\hline Maternal grandmother & 8 & 4 & 12 \\
\hline Maternal grandfather & 4 & 0 & 4 \\
\hline Paternal grandmother & 1 & 0 & 1 \\
\hline Paternal grandfather & 0 & 1 & 1 \\
\hline Maternal aunt & 2 & 1 & 3 \\
\hline Maternal uncle & 3 & 0 & 3 \\
\hline Paternal aunt & 1 & 0 & 1 \\
\hline Paternal uncle & 1 & 0 & 1 \\
\hline Sibling & 7 & 1,055 & 1,062 \\
\hline Unrelated & 1 & 0 & 1 \\
\hline Total & 309 & 1,641 & 1,950 \\
\hline
\end{tabular}

Table 3

Smoking Status of Adolescents and Members of Their Households

\begin{tabular}{|l|c|c|c|}
\hline & $\begin{array}{c}\text { Non-smoking } \\
\text { household members }\end{array}$ & $\begin{array}{c}\text { Smoking household } \\
\text { members }\end{array}$ & Total \\
\hline Teen non-smokers & 342 & 213 & 555 \\
\hline Teen smokers & 8 & 22 & 30 \\
\hline Total & 350 & 235 & 585 \\
\hline
\end{tabular}




\section{Summary and Discussion}

This investigation found an association between whether adolescents smoke or not and the presence of smokers in their home environment. While our results supported those previous studies that found such an association, it is worth noting that $38.4 \%$ of the non-smoking teens lived in households where at least one household member was a smoker. Clearly, while living with household members who smoke is an important influence, there are other factors that can outweigh it.
Further research on smoking among AfricanAmerican adolescents should examine the influence of smoking by household members along with such other factors as smoking by friends, exposure to tobacco education, selfesteem, etc. While cross-sectional studies such as ours may continue to contribute more to our knowledge in this area, we would urge that longitudinal studies have a greater potential for clarifying the causation of adolescent smoking.

\section{References}

Alexander, C. S., Allen, P., Crawford, M. A., and McCormick, L. K. (1999). Taking a first puff: cigarette smoking experiences among ethnically diverse adolescents. Ethnicity and Health, 4, 245-257.

Boomsma, D. I., Koopmans, J. R., Van Doornen, L. J. P., and Orlebeke, J. F. (1994). Genetic and social influences on starting to smoke: A Study of Dutch adolescent twins and their parents. Addiction, 89, 219-226.

Botvin, G. J., Baker, E., Goldberg, C. J., Dusenbury, L., and Botvin, E. M. (1992). Correlates and predictors of smoking among Black adolescents. Addictive Behaviors, 17, 97-103.

Brook, J. S., Whiteman, M., and Gordon, A. S. (1981). Maternal and personality determinants of adolescent smoking behavior. The Journal of Genetic Psychology, 139, 185-193.

Brook, J. S., Whiteman, M., Czeisler, L. J., Shapiro, J., and Cohen, P. (1997). Cigarette smoking in young adults: Childhood and adolescent personality, familial, and peer antecedents. The Journal of Genetic Psychology, 158, 172-188.

Brook, J.S., Pahl, K., and Ning, Y. (2006). Peer and parental influences on longitudinal trajectories of smoking among African Americans and Puerto Ricans. Nicotine and Tobacco Research, 8, 639651.

Burchfiel, C. M., Higgins, M. W., Keller, J. B., Butler, W. J., and Donahue, R. P. (1989). Initiation of cigarette smoking in children and adolescents of Tecumseh, Michigan. American Journal of Epidemiology, 130 (2), 410-415.

Centers for Disease Control and Prevention (1998). Tobacco use among high school students - United States, 1997. MMWR: Morbidity and Mortality Weekly Reports, 47, 229-233.

Centers for Disease Control and Prevention (2000). Trends in cigarette smoking among high school students - United States 1991-1999. MMWR: Morbidity and Mortality Weekly Report, 49, 755 758.

Centers for Disease Control and Prevention (2003). Tobacco use among middle and high school students-United States, 2002. MMWR: Morbidity and Mortality Weekly Reports, 52, 10961098.

Dornelas, E., Patten, C., Fischer, E., Decker, P. A., Offord, K., Barbagallo, J., et al, (2005). Ethnic variation in socioenvironmental factors that influence adolescent smoking. Journal of Adolescent Health, 36, 170-177.

Eaton, D. K., Kann, L., Kinchen, S., Ross, J., Hawkins, J., Harris, W. A., et al. (2006). Youth risk behavior surveillance--United States, 2005. MMWR Surveillance Summary, 55(5), 1-108.

Griesler, P. C, and Kandel, D. B. (1998). Ethnic differences in correlates of adolescent cigarette smoking. Journal of Adolescent Health, 23, 167-180.

Gritz, E. R., Prokhorov, A. V., Hudmon, K.S., Chamberlain, R. M., Taylor, W. C., DiClemente, C. C. et al. (1995). Cigarette smoking in a multiethnic population of youth: Methods and baseline findings. Preventive Medicine, 27, 365-384. 
Hesketh, T., Ding Q. J., and Tomkins, A. (2001). Smoking among youths in China. American Journal of Public Health, 91, 1653-1655.

Johnson, C. C., Li, D., Perry, C. L., Elder, J. P., Feldman, H. A., Kelder, S. H. et al. (2002). Fifth through eighth grade longitudinal predictors of tobacco use among a racially diverse cohort. Journal of School Health, 72(2), 58-64.

Kandel, D. B., and Wu, P. (1995). The contributions of mothers and fathers to the intergenerational transmission of cigarette smoking in adolescence. Journal of Research on Adolescence, 5, 225252.

Kurtz, M. E., Kurtz, J.C., Johnson, S. M., and Beverly, E. E. (1996). Exposure to environmental tobacco smoke: Perceptions of African American children and adolescents. Preventive Medicine, 25, 286292.

Lieb, R., Schreier, A., Pfister, H., and Wittchen, H. U. (2003). Maternal smoking and smoking in adolescents: a prospective community study of adolescents and their mothers. European Addiction Research, 9(3), 120-130.

Males, M. (1995). The influence of parental smoking on youth smoking: Is the recent downplaying justified? Journal of School Health, 65, 228-231.

Mokdad, A. H., Marks, J. S., Stroup, D. F., and Gerberding, J. L. (2004). Actual causes of death in the United States, 2000. Journal of the American Medical Association, 291, 1238-1245.

Palmer, A. B. (1970). Some variables contributing to the onset of cigarette smoking among junior high school students. Social Science and Medicine, 4, 359-366.

Patton, G. C., Carlin, J.B., Coffey, C., Wolfe, R., Hibbert, M., and Bowes, G. (1998). The course of early smoking: a population-based cohort study over three years. Addiction, 93, 1251-1260.

Salber, E. J., and MacMahon, B. (1961). Cigarette smoking among high school students related to social class and parental smoking habits. American Journal of Public Health, 51, 1780-1789.

Simons-Morton, B., Haynie, D. L., and Crump, A. D. (2001). Peer and parent influences on smoking and drinking among early adolescents. Health Education and Behavior, 28, 95-107.

U. S. Department of Health and Human Services. (1994). Preventing tobacco use among young people: A report of the surgeon general. Atlanta: Centers for Disease Control and Prevention.

U. S. Department of Health and Human Services. (1998). Tobacco use among U. S. racial/ethnic minority groups: A report of the surgeon general. Atlanta: Centers for Disease Control and Prevention.

Author Information

Larry J. Bell

Adolescent Health Program

Fulton County Department of Health and Wellness

David F. Duncan

Duncan \& Associates

Bowling Green, Kentucky

William H. Zimmerli*

Department of Public Health

Fort Valley State University

1005 State University Drive

Fort Valley, Georgia 31030

Ph.: 478-825-6639

E-Mail: zimmerlw@ffvsu.edu

* corresponding author 